\title{
LA TRADUCCIÓN DE TEXTOS TÉCNICOS ESPAÑOL / PORTUGUÉS: INTERFERENCIAS E (IR)RESPONSABILIDADES Gretel Eres Fernández
}

Profesora de Metodología de la Enseñanza de Español en la Facultad de Educación de la Universidad de São Paulo, Brasil

\section{Eugenia Flavian}

Comunicadora social y traductora pública de español/portugués en São Paulo, Brasil

\section{ABSTRACT}

In an article published in Cuadernos Cervantes de la Lengua Española no 36, we discuss problems and some follies found in certain printed translations on the packaging of products sold in supermarkets in various South American countries with a view to teaching Spanish as a foreign language.

Following that line of thought, we will discuss the translation of technical texts (packaging, instruction manuals and others) from the point of view of interference between languages as hereditarily and typologically close as Spanish and Portuguese. We will also focus on the importance of certain principles of contrastive analysis applied to translation when doing this type of work and using it as a basis for teaching purposes in Spanish classes, for the purpose of detecting and avoiding interference. And we will approach the professional responsibility issue by comparing sworn and technical translation requirements.

Finally, we will provide authentic examples of technical translations which could be of practical use in teaching Spanish as a foreign language.

KEYWORDS: technical translation, interference, contrastive analysis.

\section{RESUMEN}

En un artículo publicado en Cuadernos Cervantes de la Lengua Española $\mathrm{n}^{\circ}$ 36, analizamos los problemas - y unos cuantos disparates - encontrados en algunas traducciones impresas en los embalajes de productos que se venden en los supermercados de varios países de América del Sur, con miras a su aprovechamiento en las clases de E/LE.

Siguiendo la misma línea de pensamiento, esta vez analizaremos la traducción de textos técnicos (embalajes, manuales de instrucciones, y otros) desde el punto de vista de las interferencias entre dos idiomas genética y 
tipológicamente tan cercanos como lo son el portugués y el español. También nos centraremos en la importancia de algunos principios del análisis contrastivo aplicados a la traducción, sea a la hora de realizar ese tipo de trabajo, sea al usarla como base para actividades didácticas en clases de español, con el propósito de detectar y evitar dichas interferencias. Y enfocaremos el tema de la responsabilidad profesional, comparando las exigencias de la traducción jurada y la traducción técnica.

Finalmente, daremos ejemplos auténticos de traducciones técnicas que podrán tener un uso práctico en las clases de E/LE.

PALABRAS CLAVE: traducción técnica, interferencias, análisis contrastivo.

\section{LA INADECUACIÓN LINGÜÍSTICA EN ENVASES Y TEXTOS TÉCNICOS}

En otro trabajo que elaboramos hace unos cuantos años ${ }^{1}$ indicábamos el escaso cuidado que muchas empresas y traductores dedican a la traducción de textos que luego figurarán en los envases de diferentes productos. Señalábamos, en aquella ocasión, la necesidad de que tanto los profesores como los traductores cuidaran su producción (oral o escrita) puesto que su forma de expresión constituye muchas veces el principal modelo para los aprendices, en un caso, o la única fuente de información al público, en otro. Además, presentábamos propuestas didácticas fácilmente aplicables, elaboradas a partir de materiales que están al alcance de la mano, con el fin de concienciar a los estudiantes y profesores sobre las consecuencias de las interferencias y las equivocaciones lingüísticas.

Lamentablemente, seguimos encontrando el mismo tipo de problemas e inadecuaciones terminológicas y gramaticales en los embalajes, al menos en el ámbito local, pero en este artículo, además de los envases, enfocaremos otros textos técnicos presentes en nuestra vida diaria: manuales de instrucciones, manuales de operación de aparatos, folletos informativos, etc. Nuestro interés, ahora, se centra en el examen de las traducciones directas e inversas - españolportugués - desde la perspectiva de los estudios contrastivos, del papel comunicativo del lenguaje y de la responsabilidad profesional. Nuestro propósito es analizar cualitativamente algunos de esos textos y discutir las repercusiones de la inadecuación lingüística, sea para el usuario de un determinado producto, sea para la imagen de la empresa responsable, e incluso, para la enseñanza y aprendizaje del español.

1 Del Supermercado a la Clase o cómo transformar envases en material didáctico. Cuadernos Cervantes de la Lengua Española (36): 46-51, 2001. 


\section{COMUNICACIÓN VERSUS CORRECCIÓN LINGÜÍSTICA}

En Brasil, y en diversas otras partes, los enfoques comunicativos aplicados a la enseñanza y aprendizaje de lenguas extranjeras abogaron, durante algún tiempo y erróneamente, por una aceptación demasiado flexible de las inadecuaciones presentes en la producción oral y escrita de los aprendices. Inadvertidamente, muchos profesores entendían que lo más importante era la función comunicativa del lenguaje $y$, en ese sentido, la forma - gramatical ocupaba un papel secundario, cuando no se abolía totalmente de los cursos. Proliferaron los materiales didácticos que apenas incluían explicaciones gramaticales explícitas y los cursos "comunicativos", en los que supuestamente no se trataba la gramática.

Sin embargo, poco a poco profesores y estudiantes se percataron de que tal interpretación de los métodos comunicativos no atendía de forma satisfactoria a sus necesidades, ni era suficiente para desenvolverse en las distintas situaciones de uso de la lengua: ¿cómo comunicarse adecuadamente si no se conocen, por ejemplo, determinadas formas verbales?

Indicaban los enfoques comunicativos más "radicales" que se podría lograr una comunicación eficaz aunque no se hablara correctamente, desde el punto de vista de la gramática normativa. Y eso condujo a una libertad de expresión que admitía producciones de lo más insólitas que, si bien servían a la comunicación, resultaban totalmente inadecuadas en muchísimos contextos.

$\mathrm{Si}$ un extranjero dice, por ejemplo: "Mí gustar de España" le entenderán igual que si dijera "A mí me gusta España". Lo mismo si un turista dice: "Mí querer cerveza”, se la van a servir, sin duda. Parecerá que hablan como Tarzán, pero les perdonarán y la comunicación se habrá procesado. Sin embargo, si un profesional o un técnico se expresa así en una reunión, en una charla u otras situaciones de trabajo, sonará muy mal. En estos casos no se perdona el uso de formas de expresión tan simplificadas. Como tampoco se perdonan los errores en los textos (mal) traducidos, en que debería usarse un lenguaje culto.

Se concluye, pues, que la comunicación eficaz (entendida como la que logra su objetivo de transmitir un mensaje) no radica necesaria o exclusivamente en el conocimiento de formas verbales $\mathrm{u}$ otros elementos gramaticales. Porque la comunicación es un fenómeno muy amplio que abarca muchos aspectos más que las solas formas gramaticales (correctas o no).

Sin embargo, como hemos señalado, el poder comunicarse en un idioma extranjero no significa conocerlo o usarlo adecuadamente en todas las situaciones y contextos, si no se dominan, por lo menos, las nociones y reglas básicas que lo estructuran. 
Aplicando estas reflexiones a los cursos de lengua, tenemos que además de la interpretación inadecuada de algunos de los principios de los métodos comunicativos, la casi totalidad de los profesores había aprendido la lengua extranjera a partir del estudio explícito de la gramática y, por lo tanto, desconocían alternativas para su enseñanza. Los aprendices, a su vez, tampoco se encontraban a gusto y seguros en un curso en que la gramática apenas era nombrada.

Frente a tanta incertidumbre y descontentamiento, la tendencia natural hizo que se volviera a los modelos consagrados, es decir, a poner el foco de atención en la forma. Pero, a la vez, los principios comunicativos más amplios ya habían lanzado su semilla y, así, la comunicación y la capacidad de interacción en L2 era un aspecto que no podía volver a ignorarse.

Se entiende, por lo tanto, que comunicarse adecuada y eficazmente en una lengua extranjera, en diferentes contextos y situaciones, supone mucho más que comprender, hablar, leer y escribir frases correctas desde el punto de vista gramatical.

El conocimiento de otro idioma consiste, también, en saber cómo tales frases se utilizan para lograr un efecto comunicativo, y en comprender su adecuación o no a un contexto específico, es decir, además de conocer la forma, hay que conocer el uso (WIDDOWSON, 1991: 13-16).

Si el lugar de la gramática y la justa medida de su presencia en los cursos de Español como Lengua Extranjera (E/LE) no está del todo clara para gran parte del profesorado, tampoco lo está la forma de tratarla en clase, pues no es una tarea sencilla compaginar el conocimiento de reglas abstractas con su uso efectivo: en ocasiones se da más atención, importancia o espacio a uno que a otro. Por otra parte, el dominar los distintos usos lingüísticos configura una dificultad añadida, incluso para muchos profesores, principalmente si tenemos en cuenta la variedad lingüística del español hablado y escrito a lo largo y a lo ancho del mundo hispánico. Por lo tanto, si el profesor (o el profesional que trabaja con idiomas) no posee un excelente dominio del uso de la lengua que enseña o con la que trabaja, será difícil que en su actividad le dé la debida importancia a ese aspecto.

\section{PORTUGUÉS, ESPAÑOL Y LAS INTERFERENCIAS LINGÜÍSTICAS}

Las cuestiones anteriores ya serían suficientes para dar una idea de la dimensión de las dificultades presentes en el campo de la enseñanza de E/LE. Sin embargo, cuando tomamos como base para esa enseñanza un idioma como el portugués - genética y tipológicamente tan cercano al español - nos encontraremos frente a una serie de otros problemas que complican más aún esa circunstancia. 
Los intentos de reducir o paliar las dificultades de los aprendices han recorrido distintas metodologías, técnicas y estrategias, que van desde la prohibición total del uso de la lengua materna, hasta su presencia constante por no decir casi exclusiva - en clase. Y, de nuevo, el término medio muestra ser el más adecuado en la mayoría de las situaciones. Una tendencia cada vez más presente en los cursos y materiales didácticos de E/LE en Brasil ha sido considerar que la lengua materna de los estudiantes funciona como apoyo para el aprendizaje del español y a la vez facilita la manifestación de interferencias lingüísticas más o menos graves.

En la búsqueda de caminos capaces de permitir que el estudiante brasileño se apropie del español esquivando las interferencias - o evitando su fosilización - se hace más frecuente a cada día el uso de algunos principios de la Lingüística Contrastiva. No se trata, evidentemente, de predecir y evitar los errores procedentes de interferencias de la lengua materna sobre la lengua extranjera, como proponían los estudios contrastivos iniciales ${ }^{2}$. La contribución de la Lingüística Contrastiva, que hoy muchos defienden, consiste en utilizar y sacar provecho del conocimiento que el aprendiz posee de su lengua materna ${ }^{3}$.

Entre las distintas implicaciones de la lengua materna en el proceso de aprendizaje, destacan las transferencias a la lengua extranjera (lexicales, sintácticas, fonéticas, ortográficas, etc.), y aquí se distinguen las transferencias positivas, es decir, cuando las semejanzas entre los idiomas involucrados se convierten en un aspecto favorable al aprendizaje de la lengua extranjera, y las transferencias negativas o interferencias, que consisten en transportar elementos de cualquier naturaleza de la lengua materna a la extranjera, sin considerar que no se equivalen.

Si las transferencias negativas o interferencias se tratan con el debido cuidado y atención, se superan con mayor o menor dificultad considerándolas como una etapa más de los diferentes estadios de interlengua del aprendiz. Sin embargo, si no se les da el necesario tratamiento y, en consecuencia, no ocurre tal superación, el riesgo de fosilización es inminente. Lamentablemente, la incidencia de interferencias es alta en las producciones orales y escritas de muchos hablantes que manejan el portugués y el español con frecuencia y en forma simultánea.

\footnotetext{
2 Fries (1945), Weinreich (1957), Lado (1957), entre otros.

3 Véanse, a este propósito por ejemplo, Adja Balbino de Amorim Barbieri DURÃO (1999), Gretel ERES FERNÁNDEZ (2003) y CARABELA, tomos I y II (2002).
} 
ENTREC ULTURAS Número 1. ISSN: 1989-5097. Fecha de public ación: 27-03-2009

INTERFERENCIAS DEL PORTUGUÉS SOBRE EL ESPAÑOL (Y VICEVERSA) EN TEXTOS TÉCNICOS

A continuación se presentan algunos ejemplos de interferencias de un idioma sobre el otro, encontradas en textos técnicos y/o de uso común, que pueden servir como subsidio en las clases de E/LE para mostrar que las palabras o expresiones iguales o semejantes adquieren significados diferentes en el uso de cada idioma, y que esas supuestas semejanzas pueden perjudicar la comprensión.

No entramos aquí al campo de los falsos amigos, que es amplio y rico de ejemplos. Nos referimos a las interferencias sutiles o evidentes, perjudiciales o inofensivas, pero que de cualquier modo son molestas, no suenan bien y, más que eso, revelan el poco conocimiento que de uno u otro idioma posee el responsable de hacer la traducción o la escasa importancia que determinada empresa le da al consumidor final de sus productos, pues, por una razón u otra, no le ofrece información en lenguaje adecuado.

Conviene aclarar que el tipo de traducciones aquí incluidas a título de ejemplo, está a la orden del día en América Latina, particularmente en los países del Mercosur, que han firmado un pacto de exportación que exige la traducción de todos los rótulos y manuales que acompañan los productos comercializados en la región.

Además, el gran flujo de turistas entre los diversos países impulsa a traducir textos de diversa índole (menús, periódicos, guiones turísticos, tablas de precios, etc.) para atender a los extranjeros.

Una actitud encomiable desde el punto de vista turístico y de intercambio, pero lamentable desde el punto de vista traductológico.

Sino veamos:

\section{Ejemplo 1}

Menú del restaurante "La Andinita"

Calle Mitre, 135, Centro, Bariloche, Argentina.

Fragmentos del menú:

\begin{tabular}{|l|l|}
\hline Texto original en español & Texto traducido al portugués \\
\hline Jamón crudo solo & Presunto cru só \\
\hline Jamón crudo con rusa & Presunto cru com russa \\
\hline Café solo & Café só \\
\hline
\end{tabular}

Aquí el traductor "perpetró" una traducción al pie de la letra., en que "solo" (en español) y "só" (en portugués) son lo mismo. Efectivamente, son lo mismo, a veces, no en este caso. En Brasil, el "café solo" se dice "café 
preto/puro". No tiene nada que ver con la soledad. Y la "rusa" es "maionese".

Nada que ver con el país que posiblemente dio origen a ese tipo de ensalada.

\section{Ejemplo 2}

Manual de instalación de "Cabides Expambox"

\begin{tabular}{|c|c|}
\hline & \\
\hline $\begin{array}{l}\text { Instalação: } \\
\text { Faça os furos na parede, utilizando } \\
\text { broca } 8 \mathrm{~mm} \text {. Coloque a(s) bucha(s) e } \\
\text { fixe o produto, conforme indicado } \\
\text { abaixo. }\end{array}$ & $\begin{array}{l}\text { Instalación: } \\
\text { Haga los agurejos en la pared, } \\
\text { utilizando broca de } 9 \mathrm{~mm} \text {. Ponga los } \\
\text { torugos e fije el producto, conforme } \\
\text { bajo. }\end{array}$ \\
\hline $\begin{array}{l}\text { Garantia: } \\
\text { Este produto tem substituição } \\
\text { garantida se no período de } 5 \text { anos } \\
\text { apresentar qualquer defeito de } \\
\text { fabricação. Dirija-se ao revendedor } \\
\text { com o produto defeituoso e a nota } \\
\text { fiscal e será prontamente atendido.* A } \\
\text { garantia não cobre: avarias por } \\
\text { instalação incorreta do produto, } \\
\text { descuido, riscos por utilização de } \\
\text { produtos abrasivos na limpeza ou } \\
\text { manuseio inadequado. }\end{array}$ & $\begin{array}{l}\text { Garantia: } \\
\text { Este producto tiene substitucion } \\
\text { garantizada por el periodo de } 5 \text { años, } \\
\text { en el caso de que presente alguno } \\
\text { defecto de fabricación. Favor notar } \\
\text { que no se entende por defecto de } \\
\text { fabricación averias tales como: } \\
\text { instalación incorrecta del producto, } \\
\text { descuido por la utilización de } \\
\text { productos abrasivos en la limpieza, } \\
\text { manoseo inadecuado. }\end{array}$ \\
\hline
\end{tabular}

En este manual, dejando de lado los errores ortográficos y gramaticales presentes en todo el texto, nos preguntamos ¿qué serán "agurejos”, “torugos” y "conforme bajo"?

Nos preguntamos también, dónde está, en la traducción, toda la frase que hemos subrayado en el original. Se puede decir aquí que el traductor hizo más bien una adaptación del texto original, y en varios momentos distorsionó la información. Si el consumidor desea quejarse por algún defecto del producto, cuando le pidan la factura tendrá todo el derecho de decir "nadie me informó de ello". Este sería un dato importante por tratarse de una garantía.

\section{Ejemplo 3}

Encendedor de gas "Magiclik Classic Gênio" 


\begin{tabular}{|c|c|}
\hline & \\
\hline $\begin{array}{l}\text { Garantia } \\
\text { - Este produto tem garantia } \\
\text { permanente de peças vitais que } \\
\text { possibilitam o acendimento dos } \\
\text { aparelhos a gás. } \\
\text { - Não está incluso o revestimento de } \\
\text { plástico danificado por maus tratos, } \\
\text { quedas e pelo uso inadequado do } \\
\text { produto. } \\
\text { - A Magiclik não se responsabiliza } \\
\text { pelos consertos que não tenham sido } \\
\text { realizados em nossos representantes } \\
\text { credenciados. }\end{array}$ & 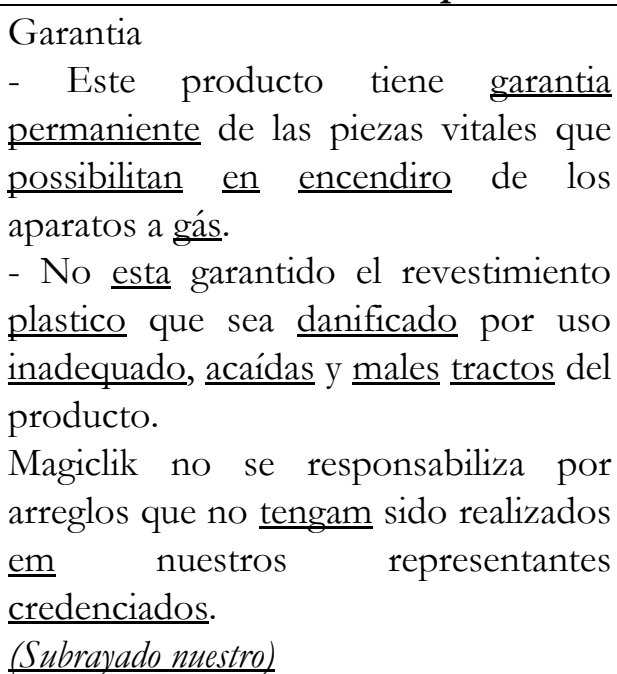 \\
\hline
\end{tabular}

Hemos subrayado en esta traducción los vocablos que presentan problemas de diversa índole: de ortografía, de acentuación, de gramática, de léxico y de inadecuación o impropiedad. No sobró casi nada...

Observamos la aplicación de algunas tendencias que terminan por convertirse en "reglas" de uso común entre muchos lusohablantes que suponen que "español es fácil". Según ellos y sus ideas faltas de fundamento, las palabras en español terminan en "niente" o "miente", porque casi todas llevan la letra " $i$ " en algún lugar. Hay quienes consideren que basta con añadir una " $c$ " antes de la " $\mathrm{t}$ " (hay también otra "regla" muy usual que consiste en transformar en "ue" lo que en portugués es "o", y en "-ción” lo que en portugués es “-ção").

Hay además una interferencia evidente en la estructura de la voz pasiva (último párrafo), que en portugués se forma con el verbo tener.

\section{Ejemplo 4}

Instrucciones para colocación de "Mix Fix"

\begin{tabular}{|c|c|}
\hline & \\
\hline $\begin{array}{l}\text { Saboneteira de Parede } \\
\text { 1. Coloque as ventosas nos } 2 \text { orificios } \\
\text { da parte de traz da saboneteira } \\
\text { pressionando-as de baixo para cima. } \\
\text { 2. Limpe a superfície lisa a ser aplicada } \\
\text { com um pano com álcool. } \\
\text { 3. As ventosas aderem melhor se }\end{array}$ & $\begin{array}{l}\text { entosas en los } 2 \\
\text { e-savon posteior y } \\
\text { hasta su posición. } \\
\text { uperficie plana con } \\
\text { hol, dejar livre del } \\
\text { adherirán meior si }\end{array}$ \\
\hline
\end{tabular}




\begin{tabular}{|l|l|}
\hline quantidade de óleo lubrificante ou & se pasa un poco de vaselina o aceite \\
mesmo de cozinha, espalhando com o & de cocina alrededor del borde de \\
dedo por toda área que fará contato & éstas. Aguardar 12hs para utilizar. \\
com a superfície. Aguarde 12hs para o & $\begin{array}{l}\text { 4. Evite colocar las ventosas sobre las } \\
\text { uso. }\end{array}$ \\
$\begin{array}{l}\text { 4. Eviones de los azulejos. } \\
\text { juntas dos azulejos. } \\
\text { (Subrayado nuestro) }\end{array}$ & (Subrayado nuestro) \\
\hline
\end{tabular}

En primer lugar, parece que el traductor se equivocó de idioma y empezó su traducción en francés...

Luego vemos que "pressionar de baixo para cima" no es lo mismo que "deslizar hacia arriba". "Óleo lubrificante" es diferente de "vaselina". Y "espalhar com o dedo por toda a área que fará contato com a superfície" no es lo mismo que sólo "alrededor del borde".

Aquí también hay una oración entera que el traductor ignoró por completo, además de errores ortográficos también en portugués, idioma que, se supone, conoce bien...

Se ve que estamos delante de un traductor con gran capacidad de invención, y será una suerte si el consumidor consigue instalar la tal jabonera basándose en la traducción de estas instrucciones.

A pesar de todo lo anterior, no se le puede echar siempre la culpa al traductor (aunque lo más común es hacerlo). El que conoce portugués notará fácilmente los errores que ocurren en los mismos originales. Porque en materia de textos, informes y proyectos, hay un elemento del que pocos se acuerdan: es necesario saber redactar. De lo contrario, ocurren producciones como la siguiente:

Ejemplo 5

\begin{tabular}{|c|c|}
\hline Texto original en portugués & Texto traducido al español \\
\hline DESCRIÇÃO DO PROJETO & $\begin{array}{l}\text { DESCRIPCIÓN } \\
\text { PROYECTO }\end{array}$ \\
\hline 1. Objetivo & 1. Objetivo \\
\hline $\begin{array}{l}\text { Este projeto tem como principal } \\
\text { objetivo potencializar a } \\
\text { comercialização dos produtos } \\
\text { Kellogg's em clientes atuantes no } \\
\text { canal de } 10 \text { a } 49 \text { check-outs, que hoje } \\
\text { são atendidos por Distribuidores/ }\end{array}$ & $\begin{array}{l}\text { Este proyecto tiene como objetivo } \\
\text { principal potenciar la comercialización } \\
\text { de los productos Kellogg's entre los } \\
\text { clientes que actúan en el canal de } 10 \text { a } \\
49 \text { check-outs (cajas de pago), a quienes }\end{array}$ \\
\hline
\end{tabular}


ENTREC ULTURAS Número 1. ISSN: 1989-5097. Fecha de public ación: 27-03-2009

Service Provider, transformando-os em clientes de Venda Direta. Assim sendo, passarão a ser atendidos de forma personalizada e estratégica do mesmo modo que os atuais Key Accounts e explorando ao máximo seu potencial, aumentando seus índices de volume e incrementando sua representatividade de Gross Profit versus Net Sales (\%). hoy atienden los Distribuidores y Service Provider (proveedores de servicios), para convertirlos en clientes de Venta Directa. Así recibirán atención personalizada y estratégica, al igual que las actuales Key Accounts (cuentas clave), y podrán explotar su potencial al máximo, aumentar sus volúmenes e incrementar su representatividad de Gross Profit versus Net Sales (\%) (ganancia bruta versus venta neta).

\section{Fuente: Proyecto de Kellogg's para el Mercosur, marzo, 2005}

Aquí el traductor hizo verdaderos milagros y trató de dar coherencia a una información sumamente confusa. El texto original en portugués, con toda la secuencia de gerundios, no permite establecer cuáles son las oraciones principales y las subordinadas. Cuáles son las acciones propulsoras y las derivadas. Además los términos en inglés, que tal vez sean de uso común en la sucursal brasileña, podrán no serlo en las sucursales latinoamericanas. Se nota la preocupación del traductor en hacer que el significado sea accesible a los lectores en otros países.

\section{CUESTIÓN DE RESPONSABILIDAD: TRADUCCIÓN PÚBLICA VERSUS TRADUCCIÓN TÉCNICA}

Gran parte de los países occidentales, la mayoría de ellos, establece algún sistema normativo para que los documentos provenientes del extranjero tengan validez en territorio nacional. Una de las exigencias suele ser la traducción. En América Latina y en España la figura del "traductor público" cumple la función de hacer la traducción fidedigna de documentos civiles o jurídicos, contratos comerciales, diplomas, certificados, demandas judiciales, balances contables, etc. Para ello necesita dominar principalmente el lenguaje jurídico y comercial. Como se dice en broma, el que puede asegurar que "um bilhão de reais" son "mil millones de pesos" es un traductor público. Por eso el profesional encargado y autorizado a dar fe del contenido de un documento escrito en idioma extranjero suele ser un traductor "jurado", que a menudo actúa con las prerrogativas (y las obligaciones) de un notario. Y por lo general, para ejercer el oficio de traductor público, el profesional se somete a algún tipo de examen en que se comprueba su conocimiento del idioma extranjero. 
En los países en donde existe la figura del traductor público, éste responde de alguna manera ante un organismo inspector y regulador que controla su trabajo. Como en toda profesión acreditada, debe respetar normas éticas y reglas de actuación.

Pero, desde el punto de vista legal, no ocurre lo mismo con el "traductor técnico".

El traductor técnico no tiene que "dar fe" de su traducción. Nadie lo controla y, en general, no está sujeto a ninguna pena si se equivoca. En parte por eso, es ahí que encontramos los disparates apuntados en este artículo (esto no significa que los traductores jurados jamás se equivoquen, pero en tales casos existe la posibilidad de interponer recurso legal, si los eventuales errores dañan o causan pérdidas a la parte interesada).

El traductor técnico es el profesional que por alguna razón comprobada o no-conoce los idiomas que necesita el cliente (entendido como el autor o responsable de un texto que requiere traducción), y se dispone a traducir los más diversos materiales: desde informes empresariales, artículos económicos y científicos, recetas de medicamentos, manuales de operación de máquinas sofisticadas, programas informáticos, hasta folletos informativos, menús, notas periodísticas, anuncios publicitarios y cartas personales.

Imagínese la amplitud y la variedad del vocabulario que debe manipular el traductor técnico. Cualquier persona que conozca un idioma, normalmente domina determinada área de la ciencia o de la técnica, ipero no todas!

Hasta aquí, defendimos el derecho al desconocimiento por parte del traductor técnico.

Pero una cosa es desconocer un vocablo (para eso están los diccionarios), o su uso más generalizado en determinado país o región (desconocer, por ejemplo, que en Argentina se dice "nafta" y "auto", para "gasolina" y "coche"), y otra cosa es inventar datos por su cuenta, omitir partes del texto, resumirlo a su manera, o cometer errores que perjudiquen la información (y, por ende, la comunicación eficaz y adecuada).

Por otra parte, ocurre que el servicio de traducción es bastante caro para América Latina, que se maneja con monedas devaluadas dentro del marco global. Por eso los pequeños comerciantes que necesitan traducir rótulos, publicaciones y otros textos de consumo, se ven obligados a recurrir a "la tía que vivió en España hace 30 años", al "primo que fue de vacaciones a Bariloche el año pasado", y así sucesivamente. En estos casos, no son los traductores profesionales quienes hacen la traducción, sino un familiar o un amigo. Y el resultado puede ser desastroso o ridículo, pero no es penalizado por las leyes locales.

Ahora bien, en el caso de las medianas y grandes compañías, que podrían contratar a un traductor habilitado, los errores y las interferencias no se justifican. Y es más: una mala traducción atestigua en contra de la empresa, y le 
da al consumidor el derecho a recurrir ante los juzgados, si fuera el caso. Ocurre que, sea por razones económicas, sea por considerar que la traducción es un asunto de menor importancia, muchas empresas acuden a una mano de obra no calificada y, a la vez, más barata que la de un profesional especializado. El contratado para traducir folletos, manuales o rótulos, en tales casos, posee algún conocimiento de los idiomas implicados, pero no siempre ese conocimiento es suficiente. $\mathrm{Y}$ sólo en raras ocasiones posee conocimientos sobre principios de traducción. Esto resulta evidente cuando vemos, en los ejemplos presentados, la supresión de oraciones enteras o la elaboración de frases a gusto y antojo del traductor. A eso se suma la similitud de los idiomas en cuestión - el portugués y el español - idiomas que, según una creencia bastante arraigada aún, "no es necesario traducir porque todos los entienden"... Los resultados saltan a la vista en los ejemplos aquí incluidos. Y no pretendemos decir, en ningún momento, que la traducción deba realizarse "al pie de la letra", sino que debe respetar las normas lexicales, gramaticales y de uso de la lengua meta, y desde luego, preservar el sentido original. (Dígase de paso que todo eso no ocurre únicamente en el sector de traducciones: en la enseñanza también, por razones económicas o por falta de profesionales, muchas veces se usa el mismo tipo de recurso, o sea, acudir a personas no capacitadas.)

\section{LAS TRADUCCIONES EN LA ENSEÑANZA DE ESPAÑOL}

Los ejemplos incluidos anteriormente ponen de manifiesto problemas de diferente índole que se encuentran con frecuencia en manuales, informes, textos publicitarios, etc. a los que tenemos acceso a diario. Además de indignarnos con los absurdos que se cometen en ellos, podemos aprovecharlos como material didáctico. No se trata de defender aquí la vuelta al Método Gramática y Traducción con todos los principios y objetivos que planteaba antes. Lo que proponemos es la utilización de materiales auténticos que tenemos al alcance de la mano - profesores y alumnos (al fin y al cabo, jtodos somos consumidores!) - como punto de partida para la realización de diferentes tipos de actividades.

Una vez que los métodos comunicativos permiten e incluso defienden la presencia de textos auténticos en los cursos de E/LE, ese tipo de material puede revelarse útil para la práctica o repaso de, por ejemplo:

a) ortografía

b) morfosintaxis

c) vocabulario

d) reglas gramaticales de todo tipo y aplicadas a todas (o casi todas) las categorías gramaticales 
e) redacción

f) identificación y corrección de errores

Evidentemente, algunos textos serán más indicados para los niveles avanzados, pero otros serán utilizables incluso en los estadios iniciales de los cursos de E/LE. Además, mejor que simplificar un texto es simplificar la actividad. Así, para alumnos que empiezan sus estudios de E/LE quizá sea preferible proponer que busquen en el diccionario los equivalentes en español para determinadas palabras del portugués, mientras que en los niveles más avanzados podremos solicitar que detecten y corrijan los errores que figuran en el texto en español o, incluso, facilitarles solamente el texto en portugués para que lo traduzcan, y luego que comparen su versión con la versión que consta en el envase o manual correspondiente. Las posibilidades son múltiples y variadas y el profesor es el indicado para elegir el tipo de actividad más adecuado en cada situación y nivel de enseñanza.

\section{CONCLUSIÓN}

Cuando se está en contacto con idiomas genética y tipológicamente tan parecidos como lo son el portugués y el español; cuando se tienen al lado variantes tan diversas del mismo idioma, como es el caso del español; cuando se convive con registros (niveles) lingüísticos tan diferentes dentro de un mismo país, por razones históricas y culturales; cuando se sufre el bombardeo de términos extranjeros en diversas áreas de la vida cotidiana, las interferencias entre los idiomas son inconmensurables y casi incontrolables.

He ahí la responsabilidad de los profesionales de lenguas: amenizar el impacto de las interferencias extranjeras, ampliar el campo de la comunicación sin perjudicar la corrección., y viceversa, fortalecer la corrección sin perjudicar la comunicación, y aceptar el cambio, que puede traer en su cerne algún tipo de evolución.

\section{REFERENCIAS BIBLIOGRÁFICAS}

ACTAS DEL I SEMINARIO DE DIFICULTADES ESPECÍfICAS PARA LA ENSEÑANZA DEL EsPaÑol A LuSOHABlantes (EsPECIAL ATENCión A LAS INTERFERENCIAS) (1993). Brasília, Embajada de España/Consejería de Educación.

CARABELA (2002): La Lingüistica Contrastiva en la enseñanza de E/LE (I y II). Madrid, SGEL.

DurÃO, A.B.de A.B (1999): Análisis de errores e interlengua de brasileños aprendices de español y de españoles aprendices de portugués. Londrina, UEL. 
ERES FERNÁNDEZ, G. (2003): Lingüística contrastiva e ensino/aprendizagem de línguas estrangeiras na atualidade: algumas relações. En: Signum - Estudos da Linguagem (6/2): 101-118. Londrina, Centro de Letras e Ciências Humanas/UEL.

FERNÁNDEZ, S. (1997): Interlengua y análisis de errores en el aprendizaje del español como lengua extranjera. Madrid, Edelsa.

Flavian, E. Y ERES FERnÁNDEZ, G. (2001): Del supermercado a la clase o cómo transformar envases en material didáctico. En: Cuadernos Cervantes de la Lengua Española, (36): 46-51, Madrid, ELR/Universidad de Alcalá.

Widdowson, H.G. (1991): O Ensino de Linguas para a Comunicação. Campinas, Pontes, (Trad.: José Carlos P. de Almeida Filho). 